\title{
Preconception care: promoting reproductive planning
}

\author{
Sohni V Dean, Zohra S Lassi, Ayesha M Imam, Zulfiqar A Bhutta*
}

\begin{abstract}
Introduction: Preconception care recognizes that many adolescent girls and young women will be thrust into motherhood without the knowledge, skills or support they need. Sixty million adolescents give birth each year worldwide, even though pregnancy in adolescence has mortality rates at least twice as high as pregnancy in women aged 20-29 years. Reproductive planning and contraceptive use can prevent unintended pregnancies, unsafe abortions and sexually-transmitted infections in adolescent girls and women. Smaller families also mean better nutrition and development opportunities, yet 222 million couples continue to lack access to modern contraception.
\end{abstract}

Method: A systematic review and meta-analysis of the evidence was conducted to ascertain the possible impact of preconception care for adolescents, women and couples of reproductive age on MNCH outcomes. A comprehensive strategy was used to search electronic reference libraries, and both observational and clinical controlled trials were included. Cross-referencing and a separate search strategy for each preconception risk and intervention ensured wider study capture.

Results: Comprehensive interventions can prevent first pregnancy in adolescence by $15 \%$ and repeat adolescent pregnancy by $37 \%$. Such interventions should address underlying social and community factors, include sexual and reproductive health services, contraceptive provision; personal development programs and emphasizes completion of education. Appropriate birth spacing (18-24 months from birth to next pregnancy compared to short intervals $<6$ months) can significantly lower maternal mortality, preterm births, stillbirths, low birth weight and early neonatal deaths.

Conclusion: Improving adolescent health and preventing adolescent pregnancy; and promotion of birth spacing through increasing correct and consistent use of effective contraception are fundamental to preconception care. Promoting reproductive planning on a wider scale is closely interlinked with the reliable provision of effective contraception, however, innovative strategies will need to be devised, or existing strategies such as communitybased health workers and peer educators may be expanded, to encourage girls and women to plan their families.

\section{Introduction}

For 1.8 billion adolescents who will be the next generation of adults, this is a pivotal time in their lives- of challenges and opportunities [1]. Preconception care recognizes that many adolescent girls and young women will be thrust into motherhood without the knowledge, skills or support they need; and that by promoting health and providing preventive care, we are investing in better outcomes for them and their children. For this review, we defined preconception care as "any intervention provided to women

\footnotetext{
* Correspondence: zulfiqar.bhutta@aku.edu

Division of Women and Child Health, Aga Khan University Karachi, Pakistan
}

and couples of childbearing age, regardless of pregnancy status or desire, before pregnancy, to improve health outcomes for women, newborns and children" (detailed discussion of the importance and scope of preconception care is given elsewhere [2]). Using the lifecycle approach to provide a continuum of care [3] ensures that gains in childhood are built upon during adolescence, and that adolescent girls and boys are prepared for their transition to becoming adults, and potentially parents. Many adolescent girls and young women face challenges such as interpersonal violence, coerced intercourse, sexually-transmitted infections (STIs) especially HIV, under-nutrition or obesity and their health consequences which makes them highly 
vulnerable. Additionally, social pressures prevent them from completing their education and force them into early marriages and childbearing. In low- and middle-income countries (LMICs), 30\% of girls are married before the age of 18 ; and worldwide approximately 16 million adolescent girls give birth, while 3 million pregnant adolescents undergo unsafe abortions [4].

Pregnancy in adolescence portends greater risk to the mother and newborn- including anemia, mortality, stillbirths, and prematurity- since adolescent girls are not yet physically mature themselves [5]. Adolescent girls are two to five times more likely to die from pregnancyrelated causes than women age 20-29 years [4]. In many contexts, their situation is further complicated by a number of factors including poverty, lack of education, restricted access to care, weak health systems that are not sensitive to their needs, abuse, unplanned or unwanted pregnancies, and the absence of autonomy or support in their social arrangement. Adolescent girls who become pregnant are limited in their educational and employment opportunities, disadvantaging themselves and their children [6]. Conversely, adolescent girls completing secondary education are less likely to marry early or get pregnant, and those who do become pregnant are more likely to have well-nourished babies who survive the neonatal period [1].

Improving health and preventing pregnancy in adolescence should be consolidated through better reproductive health for young people. Young adulthood is an opportune time in the preconception period to encourage women and couples to consider developing a reproductive plan. Reproductive planning, the freedom for women (and couples) to choose when, how often and how many children they wish to have, has a direct impact on women's health and their pregnancy outcomes. Reproductive planning is an important and fundamental component of preconception care, which could reduce adolescent pregnancy rates, and promotes spacing between pregnancies.

Reproductive planning has the potential to considerably reduce maternal, newborn, infant and child deaths. It could decrease $71 \%$ of unwanted pregnancies, thereby eliminating 22 million unplanned births, 25 million induced abortions and 7 million miscarriages [7]. Reproductive planning has other far-reaching effects. It could substantially avert sexual transmission of HIV through correct and consistent condom use. It would likely lead to smaller families, giving women more opportunities for paid employment and civic participation, and allowing parents to invest more in their children's health, education and well-being. This would further slow population growth, reduce poverty and improve development, resulting in greater equity especially in the poorest regions with the highest burden of pregnancy-related death and disability $[8,9]$.
Women and couples need access to safe, effective, acceptable and affordable methods of contraception to plan the timing, spacing and number of their children. This requires that they are well-informed of the correct and consistent use of these methods and the benefits of reproductive planning so that they are able to exercise choice and control over their own reproductive health. Counseling simultaneously ties in to reproductive planning and preconception care; so that pregnancies are more likely to be intended and appropriate healthcare services can be provided before pregnancy [10].

Millions of women and children, and future generations can benefit if we invest in preconception care (intervention targeted during pre-pregnancy and interpregnancy period) to improve adolescent health and encourage reproductive planning This paper presents the findings of a systematic review that was undertaken to consolidate the evidence for risks and interventions relating adolescent health and reproductive planning during preconception period. It begins with addressing the increased risks of pregnancy in adolescent girls and interventions to promote adolescent health and prevent teen pregnancy. The next section highlights the importance of birth spacing. An outline of pregnancy risks at advanced maternal age and genetic counseling follows. The final section illustrates how preconception counseling can be an effective means to encourage reproductive planning, reduce risk and enhance health before pregnancy.

\section{Methods}

We systematically reviewed all literature published up to 2011 to identify studies describing the effectiveness of preconception (period before pregnancy and between pregnancies) interventions and risks for adolescent health and reproductive planning on maternal, newborn and child health $(\mathrm{MNCH})$ outcomes. Electronic databases such as PubMed, Cochrane Libraries, Embase, and WHO Regional Databases were searched to identify the studies. We included systematic reviews, experimental and observational studies. Papers were also identified by hand searching references from included studies. No language or date restrictions were applied in the search. The findings were presented at international meeting $[11,12]$ and shared with professionals in the relevant fields of maternal and child health, following which results were updated based on current searches (through end of 2012) and expert opinion. Studies were included if they reported the effectiveness of interventions for promoting adolescent health and reproductive planning on MNCH outcomes. Methodology is described in detail elsewhere [2].

For the studies that met the final inclusion criteria, two review authors abstracted data describing study 
identifiers and context, study design, intervention specifics and outcome effects into a standardized abstraction sheets. The quality of experimental studies were assessed using Cochrane criteria [13], whereas STROBE guidelines were used to assess the quality of observational studies [14]. We conducted meta-analyses for individual studies and pooled statistics was reported as the odds ratio (OR) and relative risk (RR) between the experimental and control groups with 95\% confidence intervals (CI). MantelHaenszel pooled RR and corresponding 95\% CI were reported or the Der Simonian-Laird pooled RR and corresponding 95\% CI where there was an unexplained heterogeneity. All analyses were conducted using the software Review Manager 5.1 [15]. Heterogeneity was quantified by $\mathrm{Chi}^{2}$ and $\mathrm{I}^{2}$, in situations of high heterogeneity, causes were explored and random effect models were used.

\section{Results}

The review identified 1097 papers from search in all databases. After the initial title and abstract screening, 451 full texts were reviewed to identify papers which met the inclusion criteria and had the outcomes of our interest. One hundred and sixty eight studies were finally selected for abstraction and analysis (Figure 1). Information related to each included study can be found on the following link: https://globalmotherchildresearch.tghn.org/site_media/ media/articles/Preconception_Report.pdf

\section{Promoting adolescent health}

Promoting adolescent health is unquestionably important for a number of reasons [16]. Most importantly, it is the start of reproductive years and it is during the second decade of life that long-term health-related behaviors and coping strategies are formed and fixed; and certain diseases and health problems disproportionately affect adolescents, such as alcohol and substance use, STIs especially HIV/AIDS, and other reproductive health issues. Since adolescents form a significant proportion of the population, especially in LMICs, addressing their health needs is crucial to meet public health and development goals. Improving the health of adolescent girls and young women is central to achieving reductions in global maternal, newborn and childhood mortality and morbidity.

Understanding the risks that adolescents face and examining their behaviors is necessary to develop and scale-up appropriate interventions for this unique population. In many countries, a large percentage of adolescents, both married and unmarried, are sexually experienced and rates of adolescent pregnancy are high $[4,17,18]$. Determinants of adolescent health and pregnancy vary between countries and regions $[19,20]$ due in part to cultural differences, but there are also common factors (Table 1), notably low levels of contraceptive use, economic and educational disadvantage, lack of information and access to care, and cultural norms that hinder adolescent girls' independent decision-making

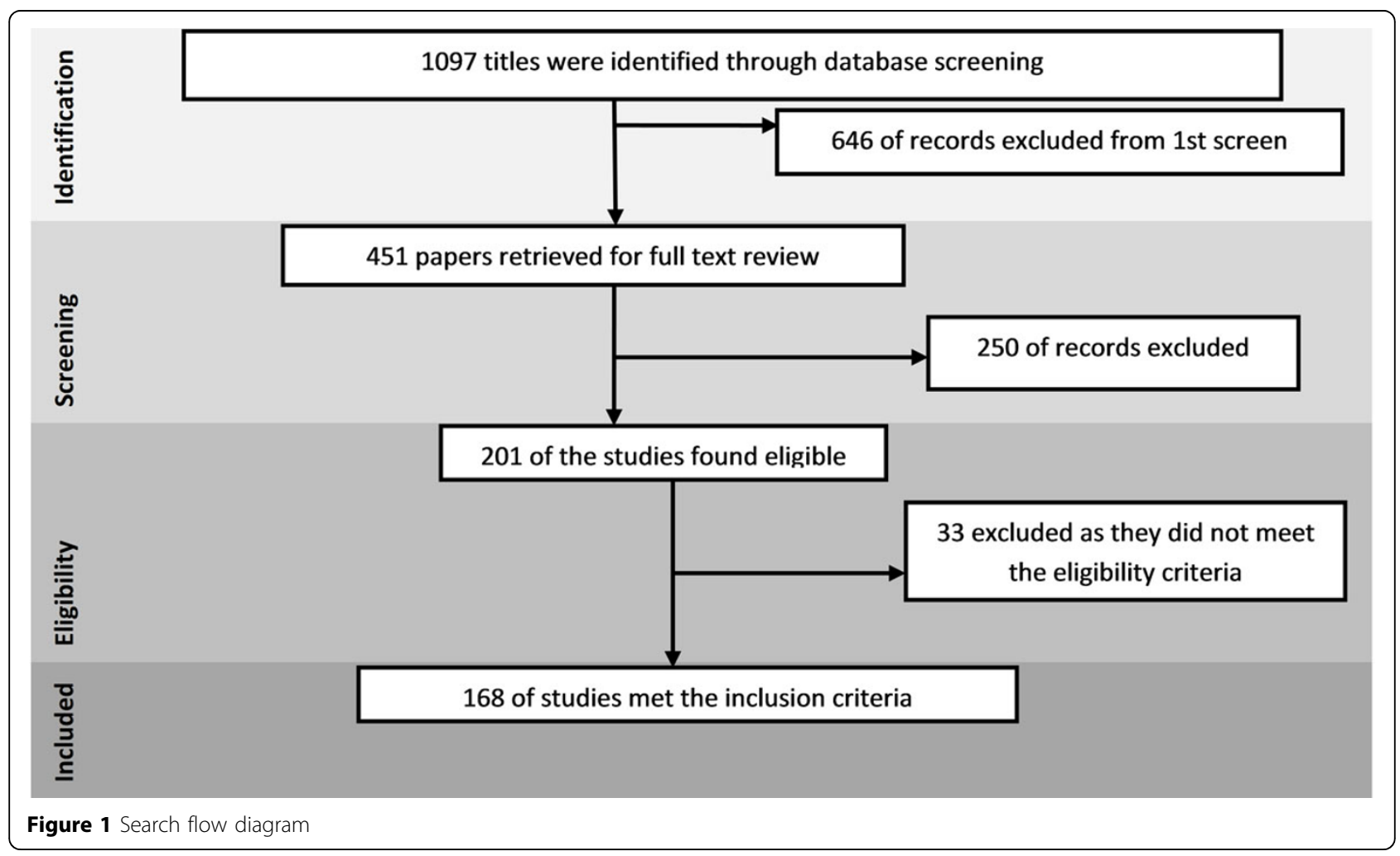


- Low use of modern contraceptive methods (other than condoms- also use OCPs and withdrawal that are unreliable)

- Lower economic and educational status and ambition

- Abuse and violence

- Alcohol and substance use

- Low self-esteem and peer-pressure or lack of decision-making power

- Lack of access

- Lack of information

- Poor relationships and lack of support systems/ family structure (Religion and extracurricular protective)

- Multiple sexual partners (especially adolescent males)

- Rapid repeat pregnancy

- Sexual coercion

- Different norms of sexual behavior for girls and boys

- Early marriage

$[17,18]$. In addition, up to $30 \%$ of women report that their first sexual experience was coerced-as adolescence is a time where patterns of sexual interaction are being learned, sexual coercion carries profound consequences. In addition to direct reproductive health consequences such as unintended pregnancy or STIs, there are myriad psychological, behavioural and social repercussions, which include subsequent high-risk sex, further experiences of interpersonal violence, and unsafe abortion [21]. In certain cultures, the practice of female genital cutting is pervasive, with 2 million girls under age 15 at risk each year. These girls develop gynaecologic problems, have higher need for obstetric intervention during childbirth, are more likely to experience post-partum haemorrhage and die, and have increased risk of stillbirths and neonatal deaths [22-24].

Adolescents face complex challenges to their well-being, and adolescent girls are particularly susceptible. Adolescent girls who become pregnant face higher mortality and morbidity, and with the largest cohort of adolescents in history, this is especially worrisome. Adolescent girls dying from pregnancy-related causes accounts for $13 \%$ of all maternal deaths. The risk of maternal mortality is twice as high for women aged 15-19 years and five times higher for girls aged 10-14 years compared to women aged 2029 years. Adolescent girls experience greater frequencies of anemia, complications of labor and delivery, and stillbirths; while their newborns are more likely to be born prematurely, have low birth weight, or die in the first month of life [4,25-27].

Given the underlying circumstances and issues, innovative interventions are needed to mitigate risk, prevent pregnancy and improve health in adolescence. Targeting adolescents and young people with preconception care provides an opportunity to increase knowledge and awareness, and influence the development of healthy behaviors and attitudes early on.

The review identified 9 studies [28-36] and two reviews $[37,38]$. One school-based prevention programme was shown to significantly reduce psychological, moderate physical and sexual dating violence perpetration, and self-reported decrease in perpetration of violence remained consistent in the long-term [28-30]. A clusterrandomised trial of another school-based intervention showed that the programme had been effective in reducing incidents of physical and emotional abuse and the symptoms of emotional distress for over a year after the programme [31]. One systematic review [37] estimated that on average, multi-component programmes reduced violence by $15 \%$ in schools that delivered the programmes compared to those that did not. Another review [38] that examined education programmes for college students found little evidence of the effectiveness of such programmes in preventing such assaults. The literature for intervention programs to prevent coerced sex and dating violence, or reduce their negative effects, largely reports on outcomes associated with a change in the level of knowledge and perceived attitudes post-intervention, but not on behaviours and actual change in the incidence or prevalence of abuse among adolescents. The programs that have been successful incorporate a significant skill-building component, in addition to addressing possible misconceptions of the causes and contributory factors relating to dating aggression.

Studies $[32,33]$ show that the education and empowerment of women is critical for abandoning the practice of female genital mutilation (FGM). Programs carried out over at least a year can increase women's resolution to not practice FGM on their daughters 1.9-2.6 times postintervention. The evidence reiterates that interventions to stop the practice of FGM are more successful [34] if they employ a human rights and development approach rather than simply increasing awareness of the consequences [35], use a participatory approach, and involve community leaders including government [36]. Overall the interventions increased the number of community members understanding the consequences of FGM and disapproving of the practice by up to 3 times.

\section{Preventing first and repeat pregnancy in adolescence}

The review identified 33 studies [39-71]. Meta-analyses were conducted of randomized controlled trials that 
intervals. For the same reason, the evidence presented for the effect of short intervals on puerperal endometritis (23\% increase), and long intervals on eclampsia ( $74 \%$ increase), third-trimester bleeding (11\% increase), and fetal death (18\% increase) must be treated with caution.

No significant effects were found for short intervals on third trimester bleeding, postpartum haemorrhage, gestational diabetes mellitus, fetal deaths, preeclampsia or eclampsia. The results for the association of long intervals with postpartum haemorrhage, premature rupture of membranes and gestational diabetes were also not significant.

We were unable to pool more than two studies for the effect of long intervals on preeclampsia which demonstrated a 74\% higher risk; however, the current evidence suggests an increased risk of $60-80 \%$ for inter-pregnancy intervals greater than 60 months [84]. Pooling results from four studies showed that short intervals increased the risk of maternal deaths by an alarming 66\% (OR 1.66, 95\% CI 1.19-2.33) (Figure 4). Short intervals also resulted in a higher frequency $(42 \%)$ of premature rupture of membranes. Women undergoing a trial of labour after a short interval were thrice as likely to suffer uterine rupture (OR 3.04, 95\% CI 1.91-4.85).

The meta-analysis found a significantly increased risk of adverse perinatal outcomes with inappropriate pregnancy spacing. Short and long intervals increased the risk of preterm birth (OR 1.45 and 1.21 respectively), low birth weight (OR 1.65 and 1.37 respectively), and small-for-gestational age (OR 1.17 and 1.18 respectively). Conde-Agudelo \& Belizan did not pool the estimates for stillbirths and neonatal death; however the meta-analysis shows an increase in stillbirths for short intervals (OR 1.42, 95\% CI 1.09-1.86) and no significant effect for long intervals [105]. Conversely, there was an increased risk of neonatal deaths with long (OR 1.15, 95\% CI 1.061.25), but not short intervals. A recent study [106] found that both short and long inter-pregnancy intervals elevate the odds of congenital defects (OR 1.15, 95\% CI 1.03-1.28 and OR 1.15, 95\% CI 1.04-1.26, respectively).
A WHO technical consultation [110] was held in 2005 to decide, based on the research evidence, what constitutes the ideal inter-pregnancy interval. Noting the effects of short intervals ( $<12$ months) and long intervals (>60 months) on maternal and perinatal outcomes, especially mortality, experts recommended a space of 18-24 months after a live birth. A recommendation for pregnancy spacing of 24 months would coincide with the optimal duration of breastfeeding, conferring added nutritional benefit in early childhood.

\section{Reproductive planning after abortion}

Many women resort to induced abortion as a desperate means of reproductive planning after an unintended pregnancy has occurred. Lack of access to services and the illegality or social unacceptability of abortion in many countries means that women often resort to crude and dangerous means to end a pregnancy [111]. Complications of unsafe abortion include incomplete abortion, hemorrhage, sepsis, uterine perforation, intra-abdominal injury, psychological trauma, infertility, reproductive tract infections, and maternal death. 21.6 million women are estimated to undergo unsafe abortions, that could be avoided through access to family planning services, and safe abortion care.Safe abortion care has the potential to save 70,000 women and prevent 5 million disabilities annually [7]. Care after an abortion includes emergency treatment of abortion complications, and provision of (or referral to) other reproductive health and counseling services [112].

The review identified 20 studies [112-131]. The included studies focused on whether women received post abortion contraceptive counseling and a contraceptive method before leaving the health facility, as well as the use of contraception at follow-up. Most studies were pre-post design and unfortunately very few reported subsequent outcomes of interest such as the incidence of repeat abortions, pregnancy complications, or length of interval before the next pregnancy. The methods of improving post-abortion care

\begin{tabular}{|c|c|c|c|c|c|c|c|}
\hline \multirow{2}{*}{$\frac{\text { Study or Subgroup }}{\text { Conde-Agudelo } 2000}$} & \multirow{2}{*}{$\frac{\text { log[Odds Ratio] }}{0.9322}$} & \multirow{2}{*}{$\begin{array}{r}\text { SE } \\
0.3741\end{array}$} & \multirow{2}{*}{$\begin{array}{r}\text { Weight } \\
21.1 \%\end{array}$} & \multirow{2}{*}{$\begin{array}{l}\text { Odds Ratio } \\
\text { IV, Fixed, } 95 \% \mathrm{Cl} \\
2.54[1.22,5.29]\end{array}$} & \multicolumn{3}{|c|}{$\begin{array}{l}\text { Odds Ratio } \\
\text { IV, Fixed, } 95 \% \mathrm{Cl}\end{array}$} \\
\hline & & & & & & & $\longrightarrow$ \\
\hline Da Vanzo 2005 & 0.4447 & 0.3874 & $19.7 \%$ & $1.56[0.73,3.33]$ & & & - \\
\hline Fortney 1998 & 0.8755 & 0.5192 & $11.0 \%$ & $2.40[0.87,6.64]$ & & & $\longrightarrow$ \\
\hline Ronsmans 1998 & 0.2624 & 0.2477 & $48.2 \%$ & $1.30[0.80,2.11]$ & & & 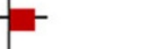 \\
\hline Total $(95 \% \mathrm{Cl})$ & & & $100.0 \%$ & $1.66[1.19,2.33]$ & & & † \\
\hline \multicolumn{4}{|c|}{$\begin{array}{l}\text { Heterogeneity: } \mathrm{Chi}^{2}=2.80, \mathrm{df}=3(\mathrm{P}=0.42) ; \mathrm{I}^{2}=0 \% \\
\text { Test for overall effect: } Z=2.95(\mathrm{P}=0.003)\end{array}$} & & 0.01 & 0.11 & $\begin{array}{rr}10 \\
\text { Short IPI }\end{array}$ \\
\hline
\end{tabular}

Figure 4 Short IPI and risk of maternal death: evidence from observational studies Citation to the included studies Conde-Agudelo 2000 [105], DaVanzo 2005 [107], Fortney 1998 [108], Ronsmans 1998 [109] 
included training healthcare providers, providing equipment and contraceptive methods, counseling partners, service reorganization and collaboration, improved follow up, linkage with other reproductive health services, and rarely increasing community awareness.

The greatest improvement in women's uptake of contraception after an abortion was seen with 2 interventions: provision of emergency treatment, contraceptive counseling, and community-service provider partnerships from $2 \%$ to $86.6 \%$ in three years; and training of providers, counseling, free contraception and follow-up resulted in $96 \%$ uptake at intervention site versus $5 \%$ at control site. The second intervention also showed that women receiving care were 3.38 times less likely to have an unplanned pregnancy, and $8 \%$ fewer repeat abortions. The least improvement (14\%) was seen in one study [116] with free contraceptive provision. This should be interpreted with caution because repeat abortions among women receiving the intervention decreased to half the rate in the general population. Counseling also creates opportunities to involve women's partners [118] by increasing the likelihood (OR 1.6) that they will support contraceptive uptake; women who receive partners' support are almost 6 times more likely to use contraception.

\section{Advanced maternal age}

Couples' decisions regarding childbearing are strongly influenced by sociocultural and economic factors. There is a growing trend towards delayed childbearing as more young people pursue higher education and desire financial independence before they start a family. Higher divorce rates and the lack of a strong support system also play a role in the decision to become a parent during later reproductive years [132]. There is a general understanding that as fertility declines, couples may have more difficulty conceiving at a later age, and that the risk of triploid disorders is increased. In addition, there may be long-term consequences for parenting behaviors [133-135].

The review compared the $\mathrm{MNCH}$ outcomes for women of any age over 35 years, with women any age between 20 and 35 years. Most of the evidence came from risk-aversion studies. Since the association of advanced maternal age and chromosomal aberrations is already well established, this data was not used.

The review identified 60 observational studies [136-195]. Pregnancy at an early age and during the later reproductive years may both influence maternal and child health outcomes. A significantly increased risk of Caesarean delivery was found with advanced maternal age (RR 1.72, 95\% CI 1.59-1.85). However, since this estimate includes elective $\mathrm{C}$-sections, the risk might simply be attributable to obstetricians, and women themselves, exercising more caution in gravidas over age 35. Although hypertension was defined differently in various studies, the risk of hypertension during pregnancy increased 3 times for women of advanced maternal age. We also found an elevated, but insignificant, risk of pre-eclampsia (OR 2.06, reduced to 1.60 when a study with very wide confidence intervals was removed from the analysis), which was taken to be a more sensitive indicator than hypertension overall in this population. The risk for antepartum hemorrhage, specifically that due to placenta previa, was significant, being approximately 3 times higher in women of advanced maternal age. The risk for maternal gestational diabetes was also significantly 3 times higher, whereas the risk for pre-gestational diabetes was increased six-fold

We also found a higher (62\%) risk of stillbirths with delayed childbearing, which is statistically significant and was derived from a total of 40 cohort and case-control studies (Figure 5). Although fewer studies were included in the meta-analyses for advanced maternal age and the risk of perinatal death (increased risk by $44 \%$; $95 \% \mathrm{CI}$ : 1.10-1.89), preterm birth (increased risk by $29 \% 95 \%$ CI: 1.14-1.46) and low birth weight (increased risk by $61 \%$; 95\% CI: 1.16-2.24), the analysis yielded significant effects for maternal age greater than 35 years on each of these outcomes.

\section{Genetic counselling}

Genetic counselling involves diagnosis, information provision/explanations, and discussion of possible options. There may be debate about what method may work best and what time may be appropriate for such an intervention to have the maximum effects. Rowley et al. reported that a patient-structured counselling method, designed to minimize negative psychological effects via discussion of feelings, was equivalent to conventional and programmed methods in terms of learning or attitude change.

Despite an extensive search we did not find studies the reported the impact of genetic counseling on maternal, newborn and child health. We only came across literature related to the attitudes and perception of couples regarding the provision of these services and the general attitude of physicians towards genetic counseling and screening in the preconception period. Our search yielded data only pertaining to cystic fibrosis, fragile $\mathrm{X}$, Tay Sachs and thalassemia.

The review identified 23 studies [198-220]. Studies on cystic fibrosis generally addressed the attitudes and perceptions of couples regarding the possibility of preconception screening. In a study where couples were asked if they would participate in a preconception screening for CF, majority replied in the affirmative [221]. However another study [204] reported a $74 \%$ acceptance rate of free preconception screening for common genetic disorders which only translated into a $2 \%$ submission rate of their blood samples. It was reported that a majority perceived no impact of carrier testing on their 
relationship status with their partner; this could generally be taken as a positive sign for support. Another study reported that carriers who had undergone had a poorer perception of their health 3 years post-testing, as compared to non-carriers $[198,199]$. Attitudes of health professionals regarding preconception CF carrier screening varied considerably. Greatest support to the notion was given by General Practitioners [200-202]; however this attitude was not translated into practice [203]. among the mode of delivery of information for population based screening, studies showed that the uptake rates were higher if the written information was given [204], if screening was offered in person by a health professional $[205,206]$ and if immediate testing was offered [206,207].

A recent review for screening for Fragile $\mathrm{X}$, found no trials to show whether offering the test to everyone is worthwhile. However studies have identified a positive attitude towards preconception screening amongst women planning a pregnancy as well as those in the general community [222] and amongst physicians [20].

Studies for premarital screening for those with hemoglobinopathies showed varying results with most reporting couples still proceeding with their marriage plans despite positive test results and counseling [208-211]; some still showed a positive effect of such programs with couples paying heed to the advice $[212,213]$. In the event of an 'inter-carriers' union, many of those who had received genetic counseling, whether in school [214-216] or elsewhere [217], sought prenatal diagnosis.

With regards to an actual effect on the disease prevalence post screening interventions, data is only available from national screening programs for thalassemia. While the genetic screening program for Thailand was unsuccessful, that of Iran deserves to be applauded. This integrated premarital screening program led to a $70 \%$ reduction in thalassemia birth rate. At risk couples were referred for counseling and were subsequently followed. Such national thalassemia prevention programs and obligatory premarital screening programs have drastically reduced thalassemia rates in these areas [212,218-220]

We found limited evidence identifying the effectiveness of any genetic screening and counseling, provided in the preconception period, in dealing with outcomes related to pregnancies. We found that couples are generally receptive to such services. This fact, and the example provided by Iran's screening program for thalassemia, needs to be utilized by health policy makers in devising comprehensive genetic counseling to all couples planning a pregnancy and genetic screening services keeping in mind the regional prevalence of genetic disorders.

\section{Discussion}

In spite of increased contraceptive coverage, many women continue to become pregnant when they do not intend to. Women may not have easy access to effective modern methods of contraception or may not use it correctly; rates of teenage pregnancy continue to be high across the world; simultaneously many women are choosing to delay initiation of childbearing; women also continue to suffer the consequences of coerced sex and intimate partner violence- these are just a few of the complex factors that lead to unintended pregnancy, and deleterious inter-pregnancy intervals. In addition to undergoing unsafe abortions, women who have unplanned pregnancies are also less likely to seek prenatal care, are more likely to engage in risky behaviour such as alcohol use and smoking, and are more likely to become depressed. When women carry these pregnancies to term, they are less likely to breastfeed or continue breastfeeding, and their children are more likely to be neglected and undernourished [223]. It seems logical that a substantial proportion of these adverse outcomes of unplanned pregnancies could be averted by bolstering efforts to meet the current contraceptive need. Comprehensive interventions that address communities, sexual and reproductive health services, contraceptive provision and school-based education; and youth development programs which promote personal development, completion of education, and community service are highly effective in preventing teenage pregnancies. The success of combining multiple interventions, especially contraception with education, has also been reported in a recent Cochrane review [224]. Systematic reviews by DiCenso et al. and Corcoran \& Pillai 2007 [225,226] confirm that the cumulative evidence for effective teenage pregnancy prevention programs is modest since programs differ in context and content. For adolescents who are already mothers, parental skills training and encouraging them to complete their education, while providing them with medical care, prevents repeat pregnancy during adolescence.

The evidence demonstrates that short inter-pregnancy intervals increases the risk of adverse perinatal outcomes, including preterm birth, low birth weight, stillbirths, maternal mortality and early neonatal deaths; while long inter-pregnancy interval heightens the risk of preeclampsia, which is a cause of maternal mortality. Some inconsistencies between the results of this review and previous work, such as the association of short inter-pregnancy intervals with anaemia and puerperal endometritis, or long inter-pregnancy intervals with eclampsia, third-trimester bleeding and fetal death, may be explained because we pooled only two studies, one of which included only women whose preceding pregnancy ended in an abortion [89]. Although the interaction between contraceptive use and pregnancy intention is complex $[227,228]$, recent reviews have found a trend toward increasing pregnancy intendedness and appropriate intervals with the use of 
contraception [229,230], however this effect does not extend to advance provision of emergency contraception [231]. Better understanding and measures of pregnancy intention, timing and wantedness are needed to increase contraceptive uptake and use [232]. Research has shown that investment in meeting the need for modern contraception in developing countries, where the burden of maternal and child mortality and morbidity is highest, would be highly cost-effective. Further, these two interventions would greatly contribute to improving adolescent health, women's health and health equity overall. Birth spacing is itself an intervention with evidence to support its effect on maternal mortality and important perinatal outcomes, yet while it is strongly recommended, there remains a need for development of strategies to promote birth spacing before first pregnancy, during pregnancy and between pregnancies

The studies overall demonstrate that post abortion care successfully increases contraceptive uptake among approximately $90 \%$ of women who receive it, as well as their partners' support and participation in family planning, however more evidence is needed to show whether this translates to fewer unintended pregnancies and fewer abortions.

Previous reviews have suggested that with advanced maternal age, the presence of comorbidities -especially diabetes and hypertension- increases, and this might largely be responsible for the pregnancy outcomes in women who delay childbearing. Schoen \& Rosen 2009 [233] also reported significantly increased risks of maternal complications in women who delayed pregnancy till their later reproductive years. Although the evidence shows an inherently greater risk with pregnancy at advanced maternal age, the social stimulus behind this trend might prove difficult to change, especially with the advent of assisted reproductive technology. Counselling is especially important for women with pre-existing medical conditions, such as diabetes and hypertension, since these contribute to excess morbidity during gestation. Research might provide further insight into the mechanisms of risk including possible confounders such as parity and method of conception, and possible interventions such as pre-implantation genetic diagnosis might become more accessible. At present, public health interventions can increase awareness regarding advanced parental age, allowing couples to weigh the risks and benefits of delaying childbearing [234], and quality antenatal care should be provided to those who become pregnant later.

While there was a significant impact of delaying childbearing on selected $\mathrm{MNCH}$ outcomes, these estimates must be interpreted with caution [235], since included studies considered different age cut-offs as "advanced" and comparison groups, and many studies did not explicitly separate conceptions through assisted reproduction. Perhaps as this population grows in number, larger prospective studies that control for confounders will substantiate whether advanced maternal age really is an independent risk factor for poor $\mathrm{MNCH}$ outcomes. Although the evidence shows an inherently greater risk with pregnancy at advanced maternal age, the social stimulus behind this trend might prove difficult to change, especially with the advent of assisted reproductive technology. Counselling is especially important for women with pre-existing medical conditions, such as diabetes and hypertension, since these contribute to excess morbidity during gestation. Research might provide further insight into the mechanisms of risk including possible confounders such as parity and method of conception, and possible interventions such as pre-implantation genetic diagnosis might become more accessible. At present, public health interventions can increase awareness regarding advanced parental age, allowing couples to weigh the risks and benefits of delaying childbearing [234], and quality antenatal care should be provided to those who become pregnant later.

Although limited evidence [218] was found on genetic screening and counseling, it was reported that couples are generally receptive to such services. Therefore, comprehensive genetic counseling to all couples planning a pregnancy and genetic screening services to women is worthy particularly for those where the regional prevalence of genetic disorders are high. Providing preconception care that incorporates reproductive planning and genetic counseling can positively influence health in adolescents, young women and couples, and avert many negative $\mathrm{MNCH}$ outcomes over the next generation.

\section{Conclusion}

Early marriage, risky sexual behaviors, delayed childbearing, and lack of access to contraception or safe abortion care mean that girls/women experience disproportionately high rates of intrapartum complications, stillbirths, neonatal deaths, prematurity and low birth weight. Among the risks and interventions reviewed, two are strongly recommended: programs to prevent first and repeat pregnancy during adolescence, and strategies to promote appropriate spacing between pregnancies through increasing uptake and consistent use of effective contraception. The successful implementation can be achieved through programs such as personal development and community service; school-based sexual and reproductive health education; and contraceptive provision. Whereas some promising interventions such as contraceptive counseling integrated into safe abortion care and conditional cash transfers to keep adolescent girls in school need further evaluation, increasing delivery and coverage of proven interventions through preconception care should now become a priority. 
Programs to prevent adolescent pregnancy can be adapted to different contexts, and scaled up in those contexts where they have previously been piloted. Promoting reproductive planning on a wider scale is closely interlinked with the reliable provision of effective contraception, however innovative strategies will need to be devised, or existing strategies to promote maternal, newborn and child health (such as community-based health workers and peer educators) may be expanded, to encourage girls and women to consider how they wish to plan their family.

\section{Peer review}

Peer review reports are included in additional file 1.

\section{Additional material}

Additional file 1: Peer review reports.

\section{Competing interests}

We do not have any financial or non-financial competing interests for this review.

\section{Acknowledgment}

The publication of these papers and supplement was supported by an unrestricted grant from The Partnership for Maternal, Newborn and Child Health.

\section{Declarations}

This article has been published as part of Reproductive Health Volume 11 Supplement 2, 2014: Preconception interventions. The full contents of the supplement are available online at http://www.reproductive-health-journal. $\mathrm{com} /$ supplements/11/S3. Publication charges for this collection were funded by the Partnership for Maternal, Newborn \& Child Health (PMNCH).

Published: 26 September 2014

\section{References}

1. Unicef: The State of the World's Children 2011: Adolescence: An Age of Opportunity [http://www.unicef.org/adolescence/files/ SOWC_2011_Main_Report_EN_02242011.pdf]:. Unicef; 2011.

2. Dean SV, Lassi ZS, Imam AM, Bhutta ZA: Preconception Care: closing the gap in the continuum of care to accelerate improvements in maternal, newborn and child health. Reproductive Health 2014.

3. Kerber KJ, de Graft-Johnson JE, Bhutta ZA, Okong P, Starrs A, Lawn JE: Continuum of care for maternal, newborn, and child health: from slogan to service delivery. Lancet 2007, 370(9595):1358-1369.

4. WHO: Adolescent pregnancy -Unmet needs and undone deeds. 2007.

5. Malabarey : Pregnancies in Young Adolescent Mothers: A PopulationBased Study on 37 Million Births. 2012.

6. Black AY, Fleming NA, Rome ES: Pregnancy in adolescents. Adolesc Med State Art Rev 2012, 23(1):123-138.

7. Who: Packages of Interventions for Family Planning, Safe Abortion care, Maternal, Newborn and Child Health whqlibdoc.who.int/hq/2010/ WHO_FCH_10.06_eng.pdf. World Health Organization; 2010.

8. WHO: Packages of interventions for family planning, save abortion care, maternal, newborn and child health. 2010.

9. Singh S, Darroch JE, Ashford LS, Vlassoff M: Adding it up: The costs and benefits of investing in family planning and maternal and newborn health. Guttmacher Institute and United Nations Population Fund. New York 2009.

10. Klerman : Family Planning Services: An Essential Component of Preconception Care. Lancet 2006.
11. Dean S, Rudan I, Althabe F, Girard AW, Howson C, Langer A, Lawn J, Reeve ME, Teela KC, Toledano M: Setting research priorities for preconception care in low-and middle-income countries: aiming to reduce maternal and child mortality and morbidity. PLOS Med 2013, 10(9):e1001508.

12. WHO WHO: Meeting to develop a global consensus on preconception care to reduce maternal and childhood mortality and morbidity. Geneva: World Health Organization Headquarters; 2012.

13. Cochrane Handbook for Systematic Reviews of Interventions. Version 5.0.0 [updated February 2008]. In The Cochrane Collaboration Higgins JPT, Green S 2008, Available from http://www.cochranehandbook.org.

14. Brand RA: Editorial: standards of reporting: the CONSORT, QUORAM, and STROBE guidelines. Clin Orthop Relat Res 2009, 467(6):1393-1394.

15. Review Manager (RevMan). [computer program]. Version 5.0: Copenhagen: Nordic Cochrane Collaboration; 2008.

16. Defo BK: The importance for the MDG4 and MDG5 of addressing reproductive health issues during the second decade of life: review and analysis from times series data of 51 African countries. Afr J Reprod Health 2011, 15(2):9-30.

17. Bearinger $L H$, Sieving RE, Ferguson J, Sharma V: Global perspectives on the sexual and reproductive health of adolescents: patterns, prevention, and potential. Lancet 2007, 369(9568):1220-1231.

18. Blanc AK, Tsui AO, Croft TN, Trevitt JL: Patterns and trends in adolescents' contraceptive use and discontinuation in developing countries and comparisons with adult women. International Perspectives on Sexual and Reproductive Health 2009, 63-71.

19. Kennedy E, Gray N, Azzopardi P, Creati M: Adolescent fertility and family planning in East Asia and the Pacific: a review of DHS reports. Reproductive Health 2011, 8(1):11.

20. Acharya $K$, Ross LF: Fragile $X$ screening: attitudes of genetic health professionals. American Journal of Medical Genetics Part A 2009, 149(4):626-632.

21. BOTT : Sexual violence and coercion: implications for sexual and reproductive health. In:. In Social determinants of sexual and reproductive health: Informing future research and programme implementation. World Health Organization: Geneva;Malarcher S 2010:

22. Adam T, Bathija H, Bishai D, Bonnenfant $Y T$, Darwish M, Huntington $D$, Johansen E: Estimating the obstetric costs of female genital mutilation in six African countries. Bulletin of the World Health Organization 2010, 88:281-288.

23. WHO: Female genital mutilation and obstetric outcome: WHO collaborative prospective study in six African countries. 2006.

24. WHO: A Systematic review of the health complications of female genital mutilation including sequelae in childbirth. 2000.

25. Paranjothy S, Broughton H, Adappa R, Fone D: Teenage pregnancy: who suffers? Archives of disease in childhood 2009, 94(3):239.

26. Chen XK, Wen SW, Fleming N, Demissie K, Rhoads GG, Walker M: Teenage pregnancy and adverse birth outcomes: a large population based retrospective cohort study. International Journal of Epidemiology 2007

27. Gibbs CM, Wendt A, Peters S, Hogue CJ: The impact of early age at first childbirth on maternal and infant health. Paediatric and perinatal epidemiology 2012, 26(s1):259-284.

28. Foshee VA, Bauman KE, Arriaga XB, Helms RW, Koch GG, Linder GF: An evaluation of Safe Dates, an adolescent dating violence prevention program. American journal of public health 1998, 88(1):45.

29. Foshee VA, Bauman KE, Greene WF, Koch GG, Linder GF, MacDougall JE: The Safe Dates program: 1-year follow-up results. American journal of public health 2000, 90(10):1619.

30. Foshee VA, Bauman KE, Ennett ST, Linder GF, Benefield T, Suchindran C: Assessing the long-term effects of the Safe Dates Program and a booster in preventing and reducing adolescent dating violence victimization and perpetration. American journal of public health 2004, 94(4):619.

31. Wolfe DA, Wekerle C, Scott K, Straatman AL, Grasley C, Reitzel-Jaffe D: Dating violence prevention with at-risk youth: a controlled outcome evaluation. Journal of Consulting and Clinical Psychology 2003, 71(2):279.

32. Igwegbe $\mathrm{AO}$, Egbuonu I: The prevalence and practice of female genital mutilation in Nnewi, Nigeria: the impact of female education. Journal of Obstetrics \& Gynecology 2000, 20(5):520-522.

33. Toubia NF, Sharief EH: Female genital mutilation: have we made progress? International Journal of Gynecology \& Obstetrics 2003, 82(3):251-261.

34. Denison E, Berg RC, Lewin S, Fretheim A: Effectiveness of interventions designed to reduce the prevalence of. Report from Kunnskapssenteret 2009, 25. 
35. WHO: Female genital mutilation: programmes to date: what works and what doesn't. A review. 1999.

36. WHO: Eliminating Female Genital Mutilation: An Interagency Statement. 2008.

37. Hahn R, Fuqua-Whitley D, Wethington H, Lowy J, Liberman A, Crosby A, Fullilove M, Johnson R, Moscicki E, Price LS: The effectiveness of universal school-based programs for the prevention of violent and aggressive behavior. Morb Mortal Wkly Rep 2007, 56:1-12.

38. Anderson JL, Waller DK, Canfield MA, Shaw GM, Watkins ML, Werler MM Maternal obesity, gestational diabetes, and central nervous system birth defects. Epidemiology 2005, 16(1):87.

39. Allen JP, Philliber S, Herrling S, Kuperminc GP: Preventing teen pregnancy and academic failure: Experimental evaluation of a developmentally based approach. Child Development 1997, 68(4):729-742.

40. Anderson R, Lois N, Koniak-Griffin D, Keenan CK, Uman G, Duggal BR, Casey C: Evaluating the outcomes of parent-child family life education. Research and Theory for Nursing Practice 1999, 13(3):211-234.

41. Boekeloo BO, Schamus LA, Simmens SJ, Cheng TL, O'Connor K, D'Angelo LJ: A STD/HIV prevention trial among adolescents in managed care. Pediatrics 1999, 103(1):107.

42. Cabezon C, Vigil P, Rojas I, Leiva ME, Riquelme R, Aranda W, Garcia C: Adolescent pregnancy prevention: An abstinence-centered randomized controlled intervention in a Chilean public high school. J Adolesc Health 2005, 36(1):64-69.

43. Eisen M, Zellman GL, MCAlister AL: Evaluating the impact of a theorybased sexuality and contraceptive education program. Family Planning Perspectives 1990, 22(6):261-271.

44. Ferguson SL: Peer counseling in a culturally specific adolescent pregnancy prevention program. Journal of Health Care for the Poor and Underserved 1998, 9(3):322-340.

45. Hahn A: Evaluation of the Quantum Opportunities Program (QOP). Did the Program Work? A Report on the Post Secondary Outcomes and Cost-Effectiveness of the QOP Program (1989-1993). 1994.

46. Handler AS: An evaluation of a school-based adolescent pregnancy prevention program. Unpublished doctoral dissertation, University of Illinois, Chicago, IL 1987

47. Herceg-Brown R, Furstenberg FF Jr, Shea J, Harris KM: Supporting teenagers' use of contraceptives: a comparison of clinic services. Family Planning Perspectives 1986, 18(2):61-66.

48. Howard M, McCabe JB: Helping teenagers postpone sexual involvement. Family Planning Perspectives 1990, 22(1):21-26.

49. Jay MS, DuRant RH, Shoffitt T, Linder CW, Litt IF: Effect of peer counselors on adolescent compliance in use of oral contraceptives. Pediatrics 1984, 73(2):126.

50. Kirby D, Korpi M, Barth RP, Cagampang HH: The impact of the Postponing Sexual Involvement curriculum among youths in California. Family Planning Perspectives 1997, 29(3):100-108.

51. Mitchell-DiCenso A, Thomas BH, Devlin MC, Goldsmith CH, Willan A, Singer J, Marks S, Watters D, Hewson S: Evaluation of an educational program to prevent adolescent pregnancy. Health Education \& Behavior 1997, 24(3):300.

52. Philliber S, Kaye J, Herrling S: The national evaluation of the Children's Aid Society Carrera-Model Program to prevent teen pregnancy. Accord, NY: Philliber Research Associates 2001.

53. Trenholm C, Devaney B, Fortson K, Quay L, Wheeler J, Clark M: Impacts of four Title V, Section 510 abstinence education programs. Princeton, NJ: Mathematica Policy Research, Inc 2007.

54. Wight D, Raab GM, Henderson M, Abraham C, Buston K, Hart G, Scott S: Limits of teacher delivered sex education: interim behavioural outcomes from randomised trial. BMJ 2002, 324(7351):1430.

55. Wu Y, Stanton BF, Galbraith J, Kaljee L, Cottrell L, Li X, Harris CV D'Alessandri D, Burns JM: Sustaining and broadening intervention impact: a longitudinal randomized trial of 3 adolescent risk reduction approaches. Pediatrics 2003, 111(1):e32.

56. Badger E, Scott KG, Field T, Robertson E: Teenage parents and their offspring. Grune \& Stratton New York; 1981

57. Black MM, Bentley ME, Papas MA, Oberlander S, Teti LO, McNary S, Le K, O'Connell M: Delaying second births among adolescent mothers: a randomized, controlled trial of a home-based mentoring program. Pediatrics 2006, 118(4):e1087.

58. Cave G: JOBSTART. Final Report on a Program for School Dropouts. 1993.
59. Elster AB, Lamb ME, Tavare J, Ralston CW: The medical and psychosocial impact of comprehensive care on adolescent pregnancy and parenthood. Jama 1987, 258(9):1187.

60. Field T, Widmayer S, Greenberg R, Stoller S: Effects of parent training on teenage mothers and their infants. Pediatrics 1982, 69(6):703.

61. Kelsey M, Johnson A, Maynard RA: The potential of home visitor services to strengthen welfare-to-work programs for teenage parents on cash assistance. Mathematica Policy Research, Inc 2001.

62. Key JD, Barbosa GA, Owens VJ: The Second Chance Club: repeat adolescent pregnancy prevention with a school-based intervention* 1 . Journal of Adolescent Health 2001, 28(3):167-169.

63. Koniak-Griffin D, Verzemnieks IL, Anderson NLR, Brecht ML, Lesser J, Kim S, Turner-Pluta C: Nurse visitation for adolescent mothers: Two-year infant health and maternal outcomes. Nursing research 2003, 52(2):127.

64. Nelson KG, Key D, Fletcher JK, Kirkpatrick E, Feinstein R: The teen-Tot clinic:: An alternative to traditional care for infants of teenaged mothers. Journal of Adolescent Health Care 1982, 3(1):19-23.

65. O'Sullivan ANNL, Jacobsen BS: A randomized trial of a health care program for first-time adolescent mothers and their infants. Nursing research 1992, 41(4):210.

66. Polit DF, Kahn JR: Project redirection: Evaluation of a comprehensive program for disadvantaged teenage mothers. Family Planning Perspectives 1985, 17(4):150-155.

67. Quint JC, Bos JM, Polit DF: New Chance. Final Report on a Comprehensive Program for Young Mothers in Poverty and Their Children. 1997.

68. Sims K, Luster TOM: Factors related to early subsequent pregnancies and second births among adolescent mothers in a family support program. Journal of Family Issues 2002, 23(8):1006.

69. Solomon R, Liefeld CP: Effectiveness of a family support center approach to adolescent mothers: Repeat pregnancy and school drop-out rates. Family Relations 1998, 47(2):139-144.

70. Wagner MM, Cameto R, Gerlach-Downie S: Intervention in support of adolescent parents and their children: A final report on the Teen Parents as Teachers Demonstration. Menlo Park, CA: SRI International 1996.

71. Wiggins M, Rosato M, Austerberry H, Sawtell M, Oliver S: Sure Start Plus National Evaluation: Final Report. 2005

72. Kirby D, Korpi M, Adivi C, Weissman J: An impact evaluation of project SNAPP: an AIDS and pregnancy prevention middle school program. AIDS Education and Prevention 1997, 9(1):44-61.

73. Ross DA: Approaches to sex education: peer-led or teacher-led? PLoS Med 2008, 5(11):e229.

74. Raymond EG, Trussell J, Polis CB: Population effect of increased access to emergency contraceptive pills: a systematic review. Obstetrics \& Gynecology 2006, 109(1):181.

75. Raine TR, Harper CC, Rocca CH, Fischer R, Padian N, Klausner JD, Darney PD: Direct access to emergency contraception through pharmacies and effect on unintended pregnancy and STIs: a randomized controlled trial. Jama 2005, 293(1):54.

76. Harper CC, Cheong M, Rocca CH, Darney PD, Raine TR: The effect of increased access to emergency contraception among young adolescents. Obstetrics \& Gynecology 2005, 106(3):483.

77. Baird S, Chirwa E, Mclntosh C, Özler B: The short term impacts of a schooling conditional cash transfer program on the sexual behavior of young women. Health Economics 2010, 19(S1):55-68.

78. Phillips KR: BrdsNBz: a text-messaging forum for improving the sexual health of adolescents in North Carolina. NC Med J 2010, 71(4):368-371.

79. Stevens-Simon C, Kelly L, Singer D: Preventing repeat adolescent pregnancies with early adoption of the contraceptive implant. Family Planning Perspectives 1999, 31(2):88-93.

80. Countdown to 2015 maternal, newborn and child survival; Building a Future for Women and Children The 2012 Report [http://www. countdown2015mnch.org/documents/2012Report/2012-Complete.pdf]. 2012.

81. Sedgh G, Singh S, Shah $\mathbb{H}$, Ahman E, Henshaw SK, Bankole A: Induced abortion: incidence and trends worldwide from 1995 to 2008. Obstetrical \& gynecological survey 2012, 67(6):341-342.

82. Fedrick J, Adelstein P: Influence of pregnancy spacing on outcome of pregnancy. British Medical Journal 1973, 4(5895):753.

83. Conde-Agudelo A, Rosas-Bermúdez A, Kafury-Goeta AC: Birth spacing and risk of adverse perinatal outcomes: a meta-analysis. JAMA 2006, 295(15):1809. 
84. Conde-Agudelo A, Rosas-Bermúdez A, Kafury-Goeta AC: Effects of birth spacing on maternal health: a systematic review. American journal of obstetrics and gynecology 2007, 196(4):297-308.

85. Klerman LV, Cliver SP, Goldenberg RL: The impact of short interpregnancy intervals on pregnancy outcomes in a low-income population. American Journal of Public Health 1998, 88(8):1182.

86. Shults RA, Arndt V, Olshan AF, Martin CF, Royce RA: Effects of short interpregnancy intervals on small-for-gestational age and preterm births. Epidemiology 1999, 10(3):250.

87. Cecatti JG, Correa-Silva EPB, Milanez H, Morais SS, Souza JP: The associations between inter-pregnancy interval and maternal and neonatal outcomes in Brazil. Maternal and Child Health Journal 2008, 12(2):275-281.

88. Conde-Agudelo A, Belizán JM, Norton MH, Rosas-Bermúdez A: Effect of the interpregnancy interval on perinatal outcomes in Latin America. Obstetrics \& Gynecology 2005, 106(2):359.

89. Conde-Agudelo A, Belizan JM, Breman R, Brockman SC, Rosas-Bermudez A: Effect of the interpregnancy interval after an abortion on maternal and perinatal health in Latin America. International Journal of Gynecology \& Obstetrics 2005, 89:S34-S40.

90. DeFranco EA, Stamilio DM, Boslaugh SE, Gross GA, Muglia LJ: A short interpregnancy interval is a risk factor for preterm birth and its recurrence. American Journal of Obstetrics and Gynecology 2007, 197(3):264.

91. Ekwo EE, Moawad A: The relationship of interpregnancy interval to the risk of preterm births to black and white women. International journal of epidemiology 1998, 27(1):68.

92. Ferraz EM, Gray $\mathrm{RH}$, Fleming PL, Maia TM: Interpregnancy interval and low birth weight: findings from a case-control study. American journal of epidemiology 1988, 128(5):1111.

93. Fuentes-Afflick E, Hessol NA: Interpregnancy interval and the risk of premature infants. Obstetrics \& Gynecology 2000, 95(3):383.

94. Grisaru-Granovsky S, Gordon ES, Haklai Z, Samueloff A, Schimmel MM: Effect of interpregnancy interval on adverse perinatal outcomes-a national study. Contraception 2009, 80(6):512-518.

95. Nabukera SK, Wingate MS, Kirby RS, Owen J, Swaminathan S, Alexander GR, Salihu HM: Interpregnancy interval and subsequent perinatal outcomes among women delaying initiation of childbearing. Journal of Obstetrics and Gynaecology Research 2008, 34(6):941-947.

96. Rodrigues $\mathrm{T}$, Barros $\mathrm{H}$ : Short interpregnancy interval and risk of spontaneous preterm delivery. European Journal of Obstetrics \& Gynecology and Reproductive Biology 2008, 136(2):184-188.

97. Smith G, Pell JP, Dobbie R: Interpregnancy interval and risk of preterm birth and neonatal death: retrospective cohort study. BMJ 2003, 327(7410):313.

98. Zhu BP, Rolfs RT, Nangle BE, Horan JM: Effect of the interval between pregnancies on perinatal outcomes. New England Journal of Medicine 1999, 340(8):589.

99. Arafa MA, Alkhouly A, Youssef ME: Influence of inter pregnancy interval on preterm delivery. Paediatric and Perinatal Epidemiology 2004, 18(4):248-252.

100. Lieberman E, Lang JM, Ryan KJ, Monson RR, Schoenbaum SC: The association of inter-pregnancy interval with small for gestational age births. Obstetrics \& Gynecology 1989, 74(1):1.

101. van Eijsden M, Smits LJM, van der Wal MF, Bonsel GJ: Association between short interpregnancy intervals and term birth weight: the role of folate depletion. American Journal of Clinical Nutrition 2008, 88(1):147.

102. DaVanzo J, Hale L, Razzaque A, Rahman M: Effects of interpregnancy interval and outcome of the preceding pregnancy on pregnancy outcomes in Matlab, Bangladesh. BJOG: An International Journal of Obstetrics \& Gynaecology 2007, 114(9):1079-1087.

103. Love ER, Bhattacharya S, Smith NC: Effect of interpregnancy interval on outcomes of pregnancy after miscarriage: retrospective analysis of hospital episode statistics in Scotland. British Medical Journal 2010, 341(aug05 2):c3967.

104. Stephansson O, Dickman PW, Cnattingius S: The influence of interpregnancy interval on the subsequent risk of stillbirth and early neonatal death. Obstetrics \& Gynecology 2003, 102(1):101.

105. Conde-Agudelo A, Belizán JM: Maternal morbidity and mortality associated with interpregnancy interval: cross sectional study. BMJ 2000, 321(7271):1255
106. Kwon S, Lazo-Escalante M, Villaran MV, Li Cl: Relationship between interpregnancy interval and birth defects in Washington State. Journal of Perinatology 2012, 32(1):45-50.

107. DaVanzo J, Razzaque A, Rahman M, Hale L, Ahmed K, Khan M, Mustafa G, Gausia K: The effects of birth spacing on infant and child mortality, pregnancy outcomes, and maternal morbidity and mortality in Matlab, Bangladesh. Santa Monica, California: RAND Working Paper 2005.

108. Fortney JA, Zhang J: Maternal death and birth spacing. Studies in Family Planning 1998, 29(4):436.

109. Ronsmans C, Campbell O: Short birth intervals don't kill women: evidence from Matlab, Bangladesh. Studies in Family Planning 1998, 29(3):282-290.

110. Marston C: Report of a WHO Technical Consultation on Birth Spacing, Geneva, Switzerland, 13-15 June 2005. World Health Organization [WHO] Geneva, Switzerland; 2006.

111. Grimes DA, Benson J, Singh S, Romero M, Ganatra B, Okonofua FE, Shah $\mid \mathrm{H}$ : Unsafe abortion: the preventable pandemic. The Lancet 2006, 368(9550):1908-1919.

112. Curtis CNM: Meeting Health Care Needs of Women Experiencing Complications of Miscarriage and Unsafe Abortion: USAID's Postabortion Care Program. 2007.

113. Thapa S, Poudel J, Padhye S: Triaging patients with post-abortion complications: a prospective study in Nepal. 2004.

114. Fetters T: An assessment of postabortion care in three regions in Ethiopia, 2000 to 2004. International Journal of Gynecology \& Obstetrics 2008, 101(1):100-106

115. Billings $\mathrm{DL}$, Benson J: Postabortion care in Latin America: policy and service recommendations from a decade of operations research. Health Policy and Planning 2005, 20(3):158.

116. Savelieva I, Pile J, Sacci I, Loganathan R: Postabortion family planning operations research study in Perm, Russia. New York, EngenderHealth; 2003.

117. David PH, Reichenbach L, Savelieva I, Vartapetova N, Potemkina R: Women's reproductive health needs in Russia: what can we learn from an intervention to improve post-abortion care? Health Policy and Planning 2007.

118. Solo J, Billings DL, Aloo-Obunga C, Ominde A, Makumi M: Creating linkages between incomplete abortion treatment and family planning services in Kenya. 1999.

119. Huntington D, Piet-Pelon NJ: Postabortion care: lessons from operations research; Postabortion care: lessons from operations research. Population Council 1999.

120. Ferreira ALCG, Souza Al, Lima RA, Braga C: Choices on contraceptive methods in post-abortion family planning clinic in the northeast Brazil. Reproductive Health 2010, 7(1):5.

121. Kestler $E$, Valencia L, Del Valle V, Silva A: Scaling up post-abortion care in Guatemala: initial successes at national level. Reproductive Health Matters 2006, 14(27):138-147.

122. Rose SB, Lawton BA, Brown SA: Uptake and adherence to long-acting reversible contraception post-abortion. Contraception 2010.

123. Johnson BR, Ndhlovu S, Farr SL, Chipato T: Reducing unplanned pregnancy and abortion in Zimbabwe through postabortion contraception. 2002

124. Rasch V, Yambesi F, Massawe S: Medium and long-term adherence to postabortion contraception among women having experienced unsafe abortion in Dar es Salaam, Tanzania. BMC Pregnancy and Childbirth 2008, 8(1):32.

125. Kestler E, Barrios B, Hernández EM, del Valle V, Silva A: Humanizing access to modern contraceptive methods in national hospitals in Guatemala, Central America. Contraception 2009, 80(1):68-73.

126. Rasch V, Yambesi F, Kipingili R: Scaling up postabortion contraceptive service-results from a study conducted among women having unwanted pregnancies in urban and rural Tanzania. Contraception 2005, 72(5):377-382.

127. Huntington D, Hassan EO, Attallah N, Toubia N, Naguib M, Nawar L: Improving the medical care and counseling of postabortion patients in Egypt. Studies in Family Planning 1995, 26(6):350-362.

128. Billings DL, Velásquez JF, Pérez-Cuevas R: Comparing the quality of three models of postabortion care in public hospitals in Mexico City. International Family Planning Perspectives 2003, 29(3):112-120. 
129. Curtis C, Huber D, Moss-Knight T: Postabortion Family Planning: Addressing the Cycle of Repeat Unintended Pregnancy and Abortion. Int Perspect Sex Reprod Health 2010, 36(1):44-48.

130. Benson J, Huapaya V, Frontiers in Reproductive H: Sustainability of postabortion care in Peru. Frontiers in Reproductive Health, Population Council 2002.

131. Medina R, Frontiers in Reproductive H: Expansion of postpartum/ postabortion contraception in Honduras. Frontiers in Reproductive Health, Population Council 2001.

132. Benzies KM: Advanced maternal age: Are decisions about the timing of child-bearing a failure to understand the risks? Canadian Medical Association Journal 2008, 178(2):183.

133. Tarin JJ, Brines J, Cano A: Long-term effects of delayed parenthood. Human Reproduction 1998, 13(9):2371.

134. Nassar AH, Usta IM: Advanced Maternal Age. Part II: Long-Term Consequences. American journal of perinatology 2009, 26(02):107-112.

135. Croen LA, Najjar DV, Fireman B, Grether JK: Maternal and paternal age and risk of autism spectrum disorders. Archives of pediatrics \& adolescent medicine 2007, 161(4):334.

136. Amarin VN, Akasheh HF: Advanced maternal age and pregnancy outcome. Eastern Mediterranean health journal= La revue de santé de la Méditerranée orientale = al-Majallah al- $i$ yah li-shara al-mutawassi 2001, 7(45):646.

137. Bell JS, Campbell DM, Graham WJ, Penney GC, Ryan M, Hall MH: Can obstetric complications explain the high levels of obstetric interventions and maternity service use among older women? A retrospective analysis of routinely collected data. BJOG: An International Journal of Obstetrics \& Gynaecology 2001, 108(9):910-918.

138. Bianco A, Stone J, Lynch L, Lapinski R, Berkowitz G, Berkowitz RL: Pregnancy outcome at age 40 and older. Obstetrics \& Gynecology 1996, 87(6):917-922.

139. Bobrowski RA, Bottoms SF: Underappreciated risks of the elderly multipara* 1. American journal of obstetrics and gynecology 1995, 172(6):1764-1770.

140. Chan BCP, Lao TTH: Effect of parity and advanced maternal age on obstetric outcome. International Journal of Gynecology \& Obstetrics 2008, 102(3):237-241.

141. Chen G, Uryasev S, Young TK: On prediction of the cesarean delivery risk in a large private practice. American journal of obstetrics and gynecology 2004, 191(2):616-623.

142. Cleary-Goldman J, Malone FD, Vidaver J, Ball RH, Nyberg DA, Comstock CH, Saade GR, Eddleman KA, Klugman S, Dugoff L: Impact of maternal age on obstetric outcome. Obstetrics \& Gynecology 2005, 105(5 Part 1):983.

143. Cnattingius R, Cnattingius S, Notzon FC: Obstacles to reducing cesarean rates in a low-cesarean setting: the effect of maternal age, height, and weight. Obstetrics \& Gynecology 1998, 92(4):501-506.

144. Delbaere I, Verstraelen H, Goetgeluk S, Martens G, De Backer G, Temmerman M: Pregnancy outcome in primiparae of advanced maternal age. European Journal of Obstetrics \& Gynecology and Reproductive Biology 2007, 135(1):41-46

145. Gilbert WM, Nesbitt TS, Danielsen B: Childbearing beyond age 40: pregnancy outcome in 24,032 cases. Obstetrics \& Gynecology 1999, 93(1):9.

146. Gordon D, Milberg J, Daling J, Hickok D: Advanced maternal age as a risk factor for cesarean delivery. Obstetrics \& Gynecology 1991, 77(4):493.

147. Jacobsson $B$, Ladfors $L$, Milsom I: Advanced maternal age and adverse perinatal outcome. Obstetrics \& Gynecology 2004, 104(4):727.

148. Jolly M, Sebire N, Harris J, Robinson S, Regan L: The risks associated with pregnancy in women aged 35 years or older. Human Reproduction 2000, 15(11):2433.

149. Joseph KS, Allen AC, Dodds L, Turner LA, Scott H, Liston R: The perinatal effects of delayed childbearing. Obstetrics \& Gynecology 2005.

150. Kirchengast $S$, Hartmann B: Advanced maternal age is not only associated with newborn somatometrics but also with the mode of delivery. Annals of human biology 2003, 30(1):1-12.

151. Lin HC, Sheen TC, Tang CH, Kao S: Association between maternal age and the likelihood of a cesarean section: a population based multivariate logistic regression analysis. Acta obstetricia et gynecologica Scandinavica 2004, 83(12):1178-1183.

152. Luke B, Brown MB: Elevated risks of pregnancy complications and adverse outcomes with increasing maternal age. Human Reproduction 2007, 22(5):1264
153. Miller DA: Is advanced maternal age an independent risk factor for uteroplacental insufficiency? American journal of obstetrics and gynecology 2005, 192(6):1974-1980

154. O'Leary CM, De Klerk N, Keogh J, Pennell C, De Groot J, York L, Mulroy S, Stanley FJ: Trends in mode of delivery during 1984-2003: can they be explained by pregnancy and delivery complications? BJOG: An International Journal of Obstetrics \& Gynaecology 2007, 114(7):855-864.

155. Prysak M, Lorenz RP, Kisly A: Pregnancy outcome in nulliparous women 35 years and older. Obstetrics \& Gynecology 1995, 85(1):65-70.

156. Roberts $C L$, Algert CS, Carnegie M, Peat B: Operative delivery during labour: trends and predictive factors. Paediatric and perinatal epidemiology 2002, 16(2):115-123.

157. Tang CH, Wu MP, Liu JT, Lin HC, Hsu CC: Delayed Parenthood and the Risk of Cesarean Delivery-Is Paternal Age an Independent Risk Factor? Birth 2006, 33(1):18-26.

158. Treacy A, Robson M, O'Herlihy C: Dystocia increases with advancing maternal age. American journal of obstetrics and gynecology 2006 195(3):760-763.

159. Yuan W, Steffensen FH, Nielsen GL, Møller M, Olsen J, Sørensen HT: A population-based cohort study of birth and neonatal outcome in older primipara. International Journal of Gynecology \& Obstetrics 2000, 68(2):113-118.

160. Ziadeh S, Yahaya A: Pregnancy outcome at age 40 and older. Archives of gynecology and obstetrics 2001, 265(1):30-33

161. Abu Heija AT, Jallad MF, Abukteish F: Maternal and perinatal outcome of pregnancies after the age of 45. Journal of Obstetrics and Gynaecology Research 2000, 26(1):27-30.

162. Astolfi P, Zonta LA: Delayed maternity and risk at delivery. Paediatric and perinatal epidemiology 2002, 16(1):67-72

163. Astolfi $P$, De Pasquale A, Zonta L: Late childbearing and its impact on adverse pregnancy outcome: stillbirth, preterm delivery and low birth weight. Revue d'épidémiologie et de santé publique 2005, 53:97-105.

164. Canterino JC, Ananth CV, Smulian J, Harrigan JT, Vintzileos AM: Maternal age and risk of fetal death in singleton gestations: USA, 1995-2000. Journal of Maternal-Fetal and Neonatal Medicine 2004, 15(3):193-197.

165. Conde-Agudelo A, Belizán JM, Díaz-Rossello JL: Epidemiology of fetal death in Latin America. Acta obstetricia et gynecologica Scandinavica 2000, 79(5):371-378.

166. Donoso E, Villarroel L: Reproductive risk of women over 40 years old]. Revista médica de Chile 2003, 131(1):55.

167. Feldman GB: Prospective risk of stillbirth. Obstetrics and gynecology 1992, 79(4):547.

168. Feresu SA, Harlow SD, Welch K, Gillespie BW: Incidence of stillbirth and perinatal mortality and their associated factors among women delivering at Harare Maternity Hospital, Zimbabwe: a cross-sectional retrospective analysis. BMC Pregnancy and Childbirth 2005, 5(1):9.

169. Fretts RC, Schmittdiel J, McLean FH, Usher RH, Goldman MB: Increased maternal age and the risk of fetal death. The New England journal of medicine 1995, 333(15):953-957.

170. Fretts RC, Usher RH: Causes of fetal death in women of advanced maternal age. Obstetrics \& Gynecology 1997, 89(1):40-45.

171. Gadow EC, Castilla EE, Lopez Camelo J, Queenan JT: Stillbirth rate and associated risk factors among 869750 Latin American hospital births 19821986. International Journal of Gynecology \& Obstetrics 1991, 35(3):209-214.

172. Glinianaia SV, Rankin J, Bell R, Pearce MS, Parker L: Temporal changes in the distribution of population risk factors attenuate the reduction in perinatal mortality. Journal of clinical epidemiology 2005, 58(12):1299-1307.

173. Haglund B, Cnattingius S, Nordström ML: Social differences in late fetal death and infant mortality in Sweden 1985-86. Paediatric and perinatal epidemiology 1993, 7(1):33-44

174. Heimann F, Messerer D, Baltzer J: Pregnancy, labor and fetal outcome in females over 40 years of age]. Geburtshilfe und Frauenheilkunde 1993, 53(6):411.

175. Khandait DW, Ambadekar NN, Zodpey SP, Vasudeo ND: Maternal age as a risk factor for stillbirth. Indian J Public Health 2000, 44(1):28-30.

176. Kristensen J, Vestergaard M, Wisborg K, Kesmodel U, Secher NJ: Pre pregnancy weight and the risk of stillbirth and neonatal death. BJOG: An International Journal of Obstetrics \& Gynaecology 2005, 112(4):403-408.

177. Lammer EJ, Brown LE, Anderka MT, Guyer B: Classification and analysis of fetal deaths in Massachusetts. JAMA: The Journal of the American Medical Association 1989, 261(12):1757. 
178. Naeye RL: Maternal age, obstetric complications, and the outcome of pregnancy. Obstetrics and gynecology 1983, 61(2):210.

179. Nybo Andersen AMN, Wohlfahrt J, Christens P, Olsen J, Melbye M: Maternal age and fetal loss: population based register linkage study. BMJ 2000, 320(7251):1708

180. Pugliese A, Vicedomini D, Arsieri R: Perinatal outcomes of newborn infants of mothers over 40 years old. A case-control study. Minerva ginecologica 1997, 49(3):81.

181. Rasmussen S, Albrechtsen S, Irgens LM, Dalaker K, Maartmann-Moe H, Vlatkovic L, Markestad T: Risk factors for unexplained antepartum fetal death in Norway 1967-1998. Early human development 2003, 71(1):39-52.

182. Raymond EG, Cnattingius S, Kiely JL: Effects of maternal age, parity, and smoking on the risk of stillbirth. BJOG: An International Journal of Obstetrics \& Gynaecology 1994, 101(4):301-306.

183. Reddy UM, Ko CW, Willinger M: Maternal age and the risk of stillbirth throughout pregnancy in the United States. American journal of obstetrics and gynecology 2006, 195(3):764-770.

184. Roman H, Robillard PY, Julien C, Kauffmann E, Laffitte A, Gabriele M, Marpeau L, Barau G: Pregnancy beyond age 40 in 382 women: a retrospective study in Reunion Island. Journal de gynécologie, obstétrique et biologie de la reproduction 2004, 33(7):615.

185. Seoud MA, Nassar AH, Usta IM, Melhem Z, Kazma A, Khalil AM: Impact of advanced maternal age on pregnancy outcome. American journal of perinatology 2002, 19(1):1.

186. Sheiner E, Hallak M, Shoham-Vardi I, Goldstein D, Mazor M, Katz M: Determining risk factors for intrapartum fetal death. The Journal of reproductive medicine 2000, 45(5):419.

187. Tough SC, Newburn-Cook C, Johnston DW, Svenson LW, Rose S, Belik J: Delayed childbearing and its impact on population rate changes in lower birth weight, multiple birth, and preterm delivery. Pediatrics 2002, 109(3):399.

188. Viegas OAC, Leong WP, Ahmed S, Ratnam SS: Obstetrical outcome with increasing maternal age. Journal of biosocial science 1994, 26(02):261-267.

189. Ziadeh SM: Maternal and perinatal outcome in nulliparous women aged 35 and older. Gynecologic and obstetric investigation 2002, 54(1):6-10.

190. Ferraz EM, Gray RH: A case-control study of stillbirths in northeast Brazil. International Journal of Gynecology \& Obstetrics 1991, 34(1):13-19.

191. Little RE, Weinberg CA: Risk factors for antepartum and intrapartum stillbirth. American journal of epidemiology 1993, 137(11):1177.

192. Meda N, Traore GS, Meda HA, Curtis V: La mortinatalité au Burkina Faso: facteurs de risque en milieu urbain de Bobo-Dioulasso. Ann Soc belge Mod trop 1991, 71:307-316.

193. Petridou E, Kotsifakis G, Revinthi K, Polychronopoulou A, Trichopoulos D: Determinants of stillbirth mortality in Greece. Sozial-und Präventivmedizin/ Social and Preventive Medicine 1996, 41(2):70-78.

194. Smeeton NC, Rona RJ, Dobson P, Cochrane R, Wolfe C: Assessing the determinants of stillbirths and early neonatal deaths using routinely collected data in an inner city area. BMC medicine 2004, 2(1):27.

195. Stephansson O, Dickman PW, Johansson ALV, Cnattingius S: The influence of socioeconomic status on stillbirth risk in Sweden. International journal of epidemiology 2001, 30(6):1296.

196. Conde-Agudelo A, Belizan JM: Risk factors for pre-eclampsia in a large cohort of Latin American and Caribbean women. BJOG 2000, 107(1):75-83

197. Stephansson O, Dickman PW, Johansson A, Cnattingius S: Maternal weight, pregnancy weight gain, and the risk of antepartum stillbirth* 1 . American journal of obstetrics and gynecology 2001, 184(3):463-469.

198. Henneman L, Bramsen I, Van der Ploeg HM, Ten Kate LP: Preconception cystic fibrosis carrier couple screening: impact, understanding, and satisfaction. Genetic Testing 2002, 6(3):195-202.

199. Axworthy D, Brock DJH, Bobrow M, Marteau TM: Psychological impact of population-based carrier testing for cystic fibrosis: 3-year follow-up. Lancet 1996, 347(9013):1443-1446.

200. Poppelaars FAM, Henneman L, Ader HJ, Cornel MC, Hermens R, Wal GVD, Kate LPT: Preconceptional cystic fibrosis carrier screening: attitudes and intentions of the target population. Genetic Testing 2004, 8(2):80-89.

201. Baars MJH, Henneman L, Kate LPT: Preconceptional cystic fibrosis carrier screening opinions of general practitioners gynecologists and pediatricians in the Netherlands. Genetic Testing 2004, 8(4):431-436

202. Faden RR, Tambor ES, Chase GA, Geller G, Hofman KJ, Holtzman NA: Attitudes of physicians and genetics professionals toward cystic fibrosis carrier screening. American journal of medical genetics 1994, 50(1):1-11.
203. Mountcastle Shah E, Holtzman NA: Primary care physicians' perceptions of barriers to genetic testing and their willingness to participate in research. American journal of medical genetics 2000, 94(5):409-416.

204. Clayton EW, Hannig VL, Pfotenhauer JP, Parker RA, Campbell PW: Lack of interest by nonpregnant couples in population-based cystic fibrosis carrier screening. American journal of human genetics 1996, 58(3):617.

205. Watson EK, Mayall E, Chapple J, Dalziel M, Harrington K, Williams C, Williamson R: Screening for carriers of cystic fibrosis through primary health care services. British Medical Journal 1991, 303(6801):504.

206. Bekker H, Modell M, Denniss G, Silver A, Mathew C, Bobrow M, Marteau T: Uptake of cystic fibrosis testing in primary care: supply push or demand pull? British Medical Journal 1993, 306(6892):1584.

207. Tambor ES, Bernhardt BA, Chase GA, Faden RR, Geller G, Hofman KJ, Holtzman NA: Offering cystic fibrosis carrier screening to an $\mathrm{HMO}$ population: factors associated with utilization. American journal of human genetics 1994, 55(4):626.

208. Almutawa FJ, Cabfm JRA: Outcome of premarital counseling of hemoglobinopathy carrier couples attending premarital services in Bahrain. old and still counting our success 2009, 217.

209. AlHamdan NAR, AlMazrou YY, AlSwaidi FM, Choudhry AJ: Premarital screening for thalassemia and sickle cell disease in Saudi Arabia. Genetics in Medicine 2007, 9(6):372.

210. Al Sulaiman A, Saeedi M, Al Suliman A, Owaidah T: Postmarital follow up survey on high risk patients subjected to premarital screening program in Saudi Arabia. Prenatal diagnosis 2010, 30(5):478-481.

211. Tamhankar PM, Agarwal S, Arya V, Kumar R, Gupta UR, Agarwal SS: Prevention of homozygous beta thalassemia by premarital screening and prenatal diagnosis in India. Prenatal diagnosis 2009, 29(1):83-88.

212. Tarazi I, Al Najjar E, Lulu N, Sirdah M: Obligatory premarital tests for thalassaemia in the Gaza Strip: evaluation and recommendations. International Journal of Laboratory Hematology 2007, 29(2):111-118.

213. Khorasani G, Kosaryan M, Vahidshahi K, Shakeri S, Nasehi MM: Results of the National Program for Prevention of -Thalassemia Major in the Iranian Province of Mazandaran. Hemoglobin 2008, 32(3):263-271.

214. Bianco I, Graziani B, Lerone M, Congedo P, Ponzini D, Braconi F, Aliquo C: A screening programme for the prospective prevention of Mediterranean anaemia in Latium: results of seven years' work. Journal of medical genetics 1984, 21(4):268.

215. Mitchell JJ, Capua A, Clow C, Scriver CR: Twenty-year outcome analysis of genetic screening programs for Tay-Sachs and beta-thalassemia disease carriers in high schools. American journal of human genetics 1996, 59(4):793.

216. Lena-Russo D, Badens C, Aubinaud M, Merono F, Paolasso C, Martini N, Mattei JF: Outcome of a school screening programme for carriers of haemoglobin disease. Journal of Medical Screening 2002, 9(2):67.

217. Ahmed S, Saleem M, Modell B, Petrou M: Screening extended families for genetic hemoglobin disorders in Pakistan. New England journal of medicine 2002, 347(15):1162-1168.

218. Samavat A, Modell B: Iranian national thalassaemia screening programme. BMJ 2004, 329(7475):1134.

219. Karimi M, Jamalian N, Yarmohammadi H, Askarnejad A, Afrasiabi $A$, Hashemi A: Premarital screening for \{beta\}-thalassaemia in Southern Iran: options for improving the programme. Journal of Medical Screening 2007, 14(2):62.

220. Bozkurt G: Results From The North Cyprus Thalassemia Prevention Program*. Hemoglobin 2007, 31(2):257-264.

221. Poppelaars FAM, Ader HJ, Cornel MC, Henneman L, Hermens R, van der Wal G, Kate LP: Attitudes of potential providers towards preconceptional cystic fibrosis carrier screening. Journal of Genetic Counseling 2004, 13(1):31-44

222. Metcalfe $S$, Jacques A, Archibald A, Burgess T, Collins V, Henry A, McNamee K, Sheffield L, Slater H, Wake S: A model for offering carrier screening for fragile $X$ syndrome to nonpregnant women: results from a pilot study. Genetics in Medicine 2008, 10(7):525.

223. Gipson JD, Koenig MA, Hindin MJ: The effects of unintended pregnancy on infant, child, and parental health: a review of the literature. Studies in Family Planning 2008, 39(1):18-38.

224. Oringanje C, Meremikwu MM, Eko H, Esu E, Meremikwu A, Ehiri JE: Interventions for preventing unin-tended pregnancies among adolescents. 2009, 1, status and date: Edited (no change to conclusions).

225. Corcoran J, Pillai VK: Effectiveness of secondary pregnancy prevention programs: A meta-analysis. Research on Social Work Practice 2007, 17(1):5. 
226. DiCenso A, Guyatt G, Willan A, Griffith L: Interventions to reduce unintended pregnancies among adolescents: systematic review of randomised controlled trials. British Medical Journal 2002, 324(7351):1426.

227. Santelli J, Rochat R, Hatfield-Timajchy K, Gilbert BC, Curtis K, Cabral R, Hirsch JS, Schieve L: The measurement and meaning of unintended pregnancy. Perspectives on Sexual and Reproductive Health 2003, 35(2):94-101.

228. Trussell J, Vaughan B, Stanford J: Are all contraceptive failures unintended pregnancies? evidence from the 1995 National Survey of Family Growth. Family Planning Perspectives 1999, 31(5):246-260.

229. Yeakey MP, Muntifering CJ, Ramachandran DV, Myint YM, Creanga AA, Tsui AO: How contraceptive use affects birth intervals: results of a literature review. Studies in Family Planning 2009, 40(3):205-214.

230. Tsui AO, McDonald-Mosley R, Burke AE: Family planning and the burden of unintended pregnancies. Epidemiologic reviews 2010, 32(1):152.

231. Polis CB, Grimes DA, Schaffer K, Blanchard K, Glasier A, Harper C: Advance provision of emergency contraception for pregnancy prevention. 2007, 3 , status and date: New search for studies and content updated (no change to conclusions).

232. Santelli J, Rochat R, Hatfield-Timajchy K, Gilbert BC, Curtis K, Cabral R, Hirsch JS, Schieve L, Unintended Pregnancy Working Group: The measurement and meaning of unintended pregnancy. Perspectives on Sexual and Reproductive Health 2003, 35(2):94-101.

233. Schoen C, Rosen T: Maternal and perinatal risks for women over 44-A review. Maturitas 2009, 64(2):109-113.

234. O'Reilly-Green C, Cohen WR: Pregnancy in women aged 40 and older. Obstetrics and gynecology clinics of North America 1993, 20(2):313.

235. Newburn-Cook CV, Onyskiw JE: Is Older Maternal Age a Risk Factor for Preterm Birth and Fetal Growth Restriction? A SystematicReview. Health Care for Women International 2005, 26(9):852-875.

doi:10.1186/1742-4755-11-S3-S2

Cite this article as: Dean et al.: Preconception care: promoting reproductive planning. Reproductive Health 2014 11(Suppl 3):S2.

\section{Submit your next manuscript to BioMed Central and take full advantage of:}

- Convenient online submission

- Thorough peer review

- No space constraints or color figure charges

- Immediate publication on acceptance

- Inclusion in PubMed, CAS, Scopus and Google Scholar

- Research which is freely available for redistribution

Submit your manuscript at www.biomedcentral.com/submit 